\title{
DIFERENTES VISÕES SOBRE A CIDADE
}

\author{
DIFFERENT VISIONS ABOUT CITY
}

\author{
Veriano Takuji Miura \\ Graduado em Comunicação Social - Publicidade e mestre em Planejamento Urbano e Regional pela \\ Universidade do Vale do Paraíba - Univap, São José dos Campos, SP
}

\section{Sandra Maria Fonseca da Costa}

Geógrafa, professora doutora do mestrado em Planejamento Urbano e Regional e diretora do Instituto de Pesquisa e Desenvolvimento da Universidade do Vale do Paraíba - Univap, São José dos Campos, SP e-mail: sandramiura@univap.br

\begin{abstract}
RESUMO
A paisagem urbana sempre exerceu um fascínio sobre os homens. Ela tem sido, ao mesmo tempo, sonho e pesadelo de um tempo. Em diferentes momentos, a paisagem urbana tem sido abordada de modo a expressar as singularidades de seu tempo. Nesse sentido, o objetivo deste artigo é trazer uma discussão sobre as diferentes visões da cidade propostas por acadêmicos, cineastas e romancistas. Desde a visão romantizada das cidades da Idade Média, de Ítalo Calvino, até as "cidades virtuais" de Pierre Lévy, destaca-se o longo percurso da chamada "aventura da modernidade".
\end{abstract}

Palavras-chave: Paisagem urbana, visões da cidade, cidades.

\begin{abstract}
The urban landscape has always applied fascination over the human society. It has been, at the same time, dream and nightmare of a time. In different moments, the urban landscape has been dealt expressing its singularities of its time. In this sense, the aim of this paper is to make a discussion about the different visions of a city that are proposed by academics, movie director and novelists. Since the romantic vision of middle age cities, of Italo Calvino, through the "virtual cities" of Pierre Lévy, it has been pointed out the long path of a called "modernity adventure".
\end{abstract}

Key words: Urban landscape, visions of city, cities.

\section{INTRODUÇÃO}

A investigação da paisagem urbana e de seus significados pode parecer, em princípio, uma atividade tão simples como as rotinas que se desenvolvem no cotidiano das pessoas. Entretanto, quando essa atividade é realizada de forma criteriosa, observando-se os diversos aspectos que a envolvem, pode converter-se em um importante levantamento sociocultural, contribuindo para os diversos setores que atuam na organização espacial das paisagens urbanas.

Este artigo, parte integrante da dissertação de mestrado intitulada Os marcos referenciais urbanos na história de São José dos Campos, São Paulo, propõe-se a tecer uma abordagem sobre a percepção ambiental, construída a partir da visão de diversos 
autores, escritores, sociólogos, geógrafos, arquitetos, antropólogos e cineastas, entre outros. A visão construída a partir da leitura e da análise das obras de personalidades de diversas áreas resultou em um texto cuja leitura pode proporcionar uma experiência imaginária por meio de paisagens diversas construídas ao longo da história, bem como a conceituação dos principais períodos da existência humana, respectivamente a antiguidade, a modernidade e a pós-modernidade.

\section{AS IMAGENS DA CIDADE NA LITERATURA E NO CINEMA}

Desde a visão romantizada das cidades da Idade Média, descritas por Italo Calvino, até as "cidades virtuais" de Pierre Lévy, destaca-se, nesse período da história, o longo percurso da chamada "aventura da modernidade". É nesse período que se configura a sociedade moderna, caracterizado pelo impulso dialético, cujos princípios se originam com o modo de produção baseado na revolução industrial e culmina com as revoluções tecnicistas das sociedades pós-industriais. Sobre o ambiente característico dessa sociedade moderna, Marshal Berman, em seu livro Tudo que é sólido desmancha no ar, descreve o chamado impulso dialético por meio de uma frase do Manifesto de Karl Marx:

"A burguesia não pode sobreviver sem revolucionar constantemente os instrumentos de produção, e com eles as relações de produção, e com eles todas as relações sociais. (...) Revolução ininterrupta da produção, contínua perturbação de todas as relações sociais, interminável incerteza e agitação, distinguem a era burguesa de todas as anteriores." (MARX apud BERMAN, 1987, p. 20)

Assim, o espírito moderno se encarrega das transformações vertiginosas ocorridas nas cidades ao longo de muitos séculos. A cidade moderna surge como palco privilegiado para as questões mais relevantes da modernidade, em especial daquelas associadas aos conflitos de seu tempo, passando a ser o lugar da luta entre as resistências do indivíduo e os processos de regulação decorrentes das racionalidades dos novos mecanismos técnico-sociais.

A emergência do chamado "meio técnico-científico informacional", conforme denominado por Milton Santos, traz também o conceito de "cidades globais", cidades que se encontram integradas ao processo de globalização. Também, os novos modelos de articulação introduzidos no espaço urbano pelas recentes técnicas de produção inerentes a esse novo meio (técnico-científico informacional) e contexto (globalização), tendem a descaracterizar a paisagem decorrente do período industrial ainda vigente. Entretanto, a descentralização característica desse modelo de produção e o aumento dos fluxos informatizados, por meio de redes telemáticas, passa a configurar um modelo espacial cuja tendência é a fragmentação do espaço.

Dessa forma, começam a perder sentido as noções de corpo social, utopia e vanguarda, inerentes ao conceito de modernidade, diante do surgimento de contextos sociais que começam a configurar-se, e que alguns autores passam a identificar como 
pós-modernidade. No que concerne às teorias espaciais, Harvey (1989) introduziu o conceito de "compressão do tempo-espaço", ou seja, o encolhimento do espaço em uma aldeia global de telecomunicações, fornecido pelas inovações nos transportes e nas comunicações. Para o autor, o tempo vem se reduzindo, a tal ponto, que passamos a assistir apenas ao evento chamado momento, ou seja, apenas o presente passa a existir.

Nessa condição pós-moderna, a cidade não é mais pensada como um todo, mas sim como uma colagem de fragmentos. Assim como no filme Blade Runner (1982), do diretor Ridley Scott, no qual a cidade de Los Angeles de 2019 é recriada como o retrato de uma cidade pós-industrial e exprime os extremos de uma sociedade de alta-tecnologia, convivendo com velhas estruturas urbanas que lutam por sua sobrevivência, mas ainda permitem o uso de espaços de convívio humano. Nesse aspecto, "Blade Runner expressa a falência do urbanismo do movimento moderno e representa também a postura pós-moderna crítica do esgotamento da cidade utópica do futuro. Por outro lado, se, literariamente, a utopia serviu historicamente como via para imaginar modelos de cidades para novas ordens sociais, as melhores representações de cidades imaginárias no cinema não são utópicas, mas distópicas", conforme atesta Gnoato (2004, p. 1).

"Blade Runner parece ter sido o último grande filme capaz de construir de maneira inovadora e consistente uma cidade imaginária e isto parece estar de acordo com a época na qual ele foi produzido, a década de oitenta, uma década na qual uma certa pós-modernidade deslumbrada com a produção sígnica da publicidade, da arte, e dos meios de comunicação em geral, apontava para a metrópole como o locus de uma excepcional vitalidade. (...) Com as cidades às voltas com a exclusão social, com a violência, com o desperdício e a deterioração da vida psíquica, restou pouco ou nenhum espaço para a sua glamourização, mas sim para as distopias que têm o seu glamour. Para comprovar, basta citar a inspiração noir de Blade Runner." (GNOATO, 2004, p. 1)

Mais recentemente, o cineasta alemão Win Wenders, falando para uma platéia de arquitetos, em Tóquio, traçou um interessante paralelo entre cidade e cinema. É sabido que os filmes Wenders, reconhecidamente um cineasta das cidades, caracterizam-se pela sensibilidade com que captam as paisagens urbanas e propiciam, ao espectador, um novo olhar sobre elas. No filme Paris, Texas, um road movie de 1984, é traçado um tratado sobre a típica espacialidade americana, no qual sobressai a indistinção entre a atmosfera rarefeita da cidade - o subúrbio - e o deserto que a circunda.

Já em Asas do desejo (1987), a protagonista é Berlim, cidade cuja densidade histórica entra, por sua vez, em profundo contraste com a ausência de historicidade da cidade americana. A primeira parte do filme examina a cidade através dos olhos monocromáticos de um par de anjos e logo chegamos a entender porque Berlim é uma cidade entre muitas em um espaço interativo global. Conforme observou Harvey (1989, p. 283), "o quadro de Berlim que emerge de sua expectativa (do diretor) é uma extraordinária paisagem de espaços fragmentados e incidentes efêmeros sem lógica coesiva. (...) Essa fantástica evocação de uma paisagem urbana, de pessoas alienadas 
em espaços fragmentados aprisionados numa efemeridade de incidentes sem padrão, tem forte efeito estético".

Em seus filmes Wenders, por assim dizer, modula o matiz da cidade com o da história e seus personagens formando um todo, no qual os recônditos da cidade revelam-se e tornam-se indissociáveis, tanto da vida dos personagens quanto da ação desenvolvida. Assim, se seus filmes retratam a paisagem humana marcada pela solidão, muito dessa caracterização se deve ao reflexo da paisagem desolada que o cineasta faz das áreas urbanas. Longe de seu olhar amoroso sobre as cidades, Wenders ainda compartilha, em seus filmes, de um certo fascínio pós-moderno pela saturação sígnica das cidades. Por fim, o que percebemos, ao ver as obras de Win Wenders, é a denúncia de ser um dos principais problemas das cidades contemporâneas o excesso de imagens. Os vazios noturnos das ruas de Berlim funcionam como recurso para realçar o brilho de néon das fachadas comerciais.

Fora das telas de cinema, as cidades também podem ser vistas como representações imagéticas. As paisagens construídas sobre as bases materiais que compõem as ruas, avenidas, monumentos e edifícios, apresentam-se como partes de um cenário pronto para ser decifrado. Embora construídas sobre uma base material, cada parte da cidade pode ser considerada como o recorte de um objeto conceitual e abstrato e, a cada momento, requer que se apresente com determinadas dimensões e existam certas relações sociais em seu interior. Sobre esse processo, Geiger (1995, p. 24) explica: "justamente por variar o conceito em torno da mesma palavra, é que aglomerados tão diversos entre si, como Ur, na antiguidade, ou Nova York, puderam ser designados pela mesma palavra cidade."

Da mesma forma, a obra de Calvino (1994), As cidades invisíveis, destaca-se por apresentar uma grande concentração de leitura de cidades, inexistentes, porém de densa visibilidade. Nessa obra, o autor toma como referencial uma cidade existente, Veneza, na ltália, para, a partir dela, então, iniciar uma série de descrições de cidades chamadas "invisíveis" pelo fato de terem sido imaginadas na mente do autor. Considerada por Ferrara $(1999$, p. 63) como "uma das mais sagazes percepções do ambiente de que se tem notícia", nessa obra, o autor demonstra ser possível "construir" diferentes cidades (na realidade, são uma, apenas), conforme se privilegiam diversos aspectos.

Em As cidades invisíveis, Calvino apresenta vários textos, em forma de romance, nos quais Marco Polo, o famoso viajante veneziano, descreve, para o imperador Kublai Khan, diversas cidades que havia visitado, como Isidora, Anastarmina, Dorotéia, Maurília, Cecília, todas com nome de mulher e, em cada uma, a linguagem mostra que podemos percorrer as ruas como se fossem as páginas escritas. Entre uma cidade e outra, não se fala dos espaços que as separam. Entre um território e outro, os intervalos não são visíveis. Percorrem-se continentes, mas o trajeto é desconhecido, só se sabe da partida e da chegada.

Assim procede o autor. Condicionando a leitura do texto à precisão dos objetivos, conduzindo o olhar do leitor que recai sobre o traçado das ruas, as torres, os sons, os 
mortos ou as pedras. O leitor pode descobrir, tal como o grande Kublai Khan, a colher, nas diversas cidades, as imagens, símbolos e caminhos que costuram o imaginário citadino, "cujos contornos dão conta de estruturas enigmáticas ainda por serem decifradas" (DANTAS, 2004, p. 2). Nesse sentido, "a cidade não conta seu passado, mas ele o contém como as linhas das mãos, escritas nos ângulos das ruas, nas grandes janelas, nos corrimãos das escadas, nas antenas dos pára-raios, nos mastros das bandeiras, em cada segmento riscado por arranhões, serradelas, entalhes, esfoladuras" (CALVINO, 1994, p. 15).

A excitação de Kublai Khan perante a narração de Marco Polo impulsiona suas narrativas a fermentarem outras, refluindo as recordações e dilatando sua imaginação, como nas Mil e uma noites. $\bigcirc$ desejo do imperador Khan é o de, após as descrições, ser possível montar um império perfeito. Fato que não pode acontecer. Diomira, Isaura, Raíssa e tantas outras são exemplos de cidades a escaparem ao controle humano, do olhar racional e aferidor. Oferecem surpresas constantes em todos os sentidos, como suas ruas e vielas que nunca podem ser traçadas no papel, sendo comparadas por Marco Polo aos "caminhos das andorinhas que cortam o ar acima dos telhados, perfazem parábolas invisíveis com asas rígidas, desviam-se para engolir um mosquito, voltam a subir em espiral rente a pináculo, sobranceiam todos os pontos da cidade de cada ponto de suas trilhas aéreas" (CALVINO, 1994, p. 84).

Ainda, referindo-se às Cidades invisíveis, e ao desejo utópico do imperador Khan, Dantas (2004, p. 2) faz, em seu artigo, a seguinte constatação: "Se por um lado, as cidades contêm mecanismos de proteção que impedem a realização do desejo de totalidade, por outro, homens, formas e símbolos constituem-se num amálgama revelador das teias simbólicas que tramam seu cotidiano e sua história." Como, então, estabelecer uma metodologia possível para a compreensão do universo das cidades? Para a autora, a resposta pode ser encontrada na sugestiva metáfora da "ponte" em que:

"Marco Polo descreve uma ponte, pedra por pedra

- Mas qual é pedra que sustenta a ponte? - Pergunta Kublai Khan

- A ponte não é sustentada por esta ou aquela pedra - responde Marco Pólo mas pela curva do arco que estas formam.

Kublai Khan permanece em silêncio, refletindo. Depois acrescenta:

- Por que falar das pedras? Só o arco me interessa.

Marco Polo responde:

- Sem pedras, o arco não existe." (CALVINO, 1994, p. 79)

A partir dessa metáfora, explica-se a impossibilidade de fazer-se a leitura das cidades a partir do isolamento dos elementos que thes dão forma, vez que, conforme Dantas (2004), "sua característica maior está em bricolar os dados materiais e espirituais que tecem e são tecidos nas relações homem/natureza". Dessa forma, os fragmentos são registros que podem passar despercebidos para um observador desatento, mas, para aquele observador de percepção aguçada, esses registros podem se transformar em ricos vestígios e lembranças da cidade, como os achados de um sítio arqueológico. 
A importância da obra de Calvino, para o estudo da percepção ambiental, também é destacada por Ferrara (1999, p. 63), em artigo no qual a autora analisa o seguinte trecho em destaque:

"Kublai Khan percebera que as cidades de Marco Polo eram todas parecidas, como se a passagem de uma para outra não envolvesse uma viagem, mas mera troca de elementos. Agora, para cada cidade que Marco Polo the descrevia, a mente do Grande Khan partia por conta própria e, desmontando a cidade pedaço por pedaço, ele a reconstruía de outra maneira, substituindo ingredientes, deslocando-os, invertendo-os.

... De uma cidade, não aproveitamos as suas sete ou setenta maravilhas, mas a resposta que dá às nossas perguntas. Ou as perguntas que colocamos para nos obrigar a responder, como Tebas na boca da Esfinge." (CALVINO, 1994, p. 43-44)

Responder a essas perguntas (encontradas em todas as cidades) é o desafio maior que se coloca ao pesquisador do ambiente urbano. Desafio que, segundo Ferrara (1999, p.63), "se multiplica em aspectos conceituais, metodológicos e propriamente empíricos". Assim, para Ferrara, aos olhos do pesquisador, as cidades acabam por se converter em um grande questionário cujas perguntas, formuladas de forma não-verbal, constituem-se no desafio maior: "o desafio da leitura não imediata, mas montada, elaborada, interpretada e revista a cada contato com a cidade, leitura que é antes de tudo um reconhecimento, porque lê o ilegível."

A riqueza de detalhes, nas obras de Calvino, é capaz de preencher o imaginário de qualquer leitor; entretanto, são diversos os aspectos e as possibilidades existentes para a abordagem de um tema tão amplo quanto o cenário das cidades. A percepção visual pode proporcionar, ao leitor, variadas possibilidades de interpretação; no entanto, a inclusão de outras modalidades de percepção, associadas a análises de contextos históricos, possibilitam a compreensão de forma ampla e abrangente do processo de formação do espaço definido como ambiente urbano.

Em seu livro Tudo o que é sólido desmancha no ar (1986), o sociólogo Marshal Berman faz uma análise da romântica novela A nova Heloísa, de Rousseau, na qual o jovem herói Saint-Preux, após realizar "um movimento exploratório - um movimento arquetípico para milhões de jovens nas épocas seguintes - do campo para a cidade", escreve para sua amada, Julie, tentando transmitir-lhe as fantasias e apreensões experimentadas por ele na vida metropolitana, a partir do centro "das profundezas do tourbillon social" que caracterizou o período classificado por Berman (1986, p. 16) como a primeira fase da modernidade?.

Depois de migrar-se para a cidade, o personagem logo passa a experimentar uma infinidade de experiências que Rousseau descreve como "um contínuo fluxo e refluxo de opiniões conflitivas, no qual todos se colocam freqüentemente em contradição consigo mesmo" e "tudo é absurdo, mas nada é chocante, porque todos se acostumam a tudo". Para o personagem, aquele é um mundo em que "o bom, o mau, o belo e o feio, a verdade e a virtude, têm uma existência apenas local e limitada". Após alguns meses 
vivendo nesse mundo no qual uma infinidade de novas experiências são oferecidas, ele escreve:

"... eu começo a sentir a embriaguez a que essa vida agitada e tumultuosa me condena. Com tal quantidade de objetos desfilando diante de meus olhos, eu vou ficando aturdido. De todas as coisas que me atrai, nenhuma toca o meu coração, embora todas juntas perturbem meus sentimentos, de modo a fazer que eu esqueça o que sou e qual seja meu lugar." (ROUSSEAU apud BERMAN 1986, p. 17)

Ele reafirma sua intenção de manter-se fiel ao seu primeiro amor, embora receie, como Berman (1986, p. 18) destaca: "Eu não sei a cada dia, o que vou amar no dia seguinte." Sonha desesperadamente com algo sólido a que se apegar, mas "eu vejo apenas fantasmas que rondam meus olhos e desaparecem assim que os tento agarrar". Para Berman, essa atmosfera "de agitação e turbulência, aturdimento psíquico e embriaguez, morais e dos compromissos pessoais (...) é a atmosfera que dá origem à sensibilidade moderna".

Ainda discorrendo a respeito da modernidade, o autor constata que, se nos adiantarmos cerca de um século na tentativa de identificar "os ritmos peculiares da modernidade do século XIX, a primeira coisa que observaremos será a nova paisagem, altamente desenvolvida, diferenciada e dinâmica, na qual tem lugar a experiência moderna". Tratase de um ambiente localizado dentro do contexto da chamada revolução industrial, na qual se destacam os "engenhos a vapor, fábricas automatizadas, ferrovias, amplas novas indústrias; prolíficas cidades que cresceram do dia para a noite".

Nesse contexto, a percepção moderna do mundo pode-se traduzir por um turbilhão de novas sensações, ocorridas no mundo e na vida cotidiana, por meio de estruturas diversas que surgem no espaço e no tempo. É também nesse mesmo contexto que surge a modernidade como conceito de ruptura com a tradição, "questão que está elaborada desde Weber, em sua teoria da modernidade como produto da racionalização, cuja ênfase no papel da acumulação do capital como plasmação do poder do tempo, está evidenciado na expressão 'time is money', e nos processos de racionalização da cultura" (FURTADO, 2002, p. 4).

Analisando essa mesma questão, as cidades no contexto da modernidade (LIMENA, 2004, p. 42), observa: "a metrópole representada, evocada ou reinventada pelos artistas, literatos e cineastas, desde o final do século XIX até nossos dias, suscita interpretações múltiplas e contraditórias", revelando metamorfoses profundas dos modos de apropriação material e simbólica dos elementos vitais do cotidiano e do imaginário urbano, resultando em imagens paradigmáticas. Para a autora, a interpretação das cidades no olhar do artista revela "qualificações" do espaço urbano, que podem convergir ou contrapor-se com a interpretação de urbanistas e arquitetos.

Abordando o aspecto da produção artística e cultural, no campo da percepção ambiental, Limena (2004, p. 42) observa que os "artistas, escritores e cineastas aparecem como portadores de um pensamento e um conhecimento que sintetizam, simultaneamente, uma realidade material e ideal". Para a autora, as artes têm a capacidade 
de produzir imagens cujos conteúdos são capazes de fornecer um sentido de tempo e de lugar e a partir do qual se pode construir "não apenas um sentido de orientação para movimentação no espaço da cidade, mas também formas de compreensão da realidade cultural e sociopolítica que apresenta".

Dessa forma, o recurso à literatura, às artes plásticas e ao cinema permite um processo de compreensão que evidencia uma forte correspondência entre a apropriação material e simbólica, constituindo-se em obras, elaboradas a partir de experiências polissensoriais e dinâmicas "a partir de estruturas denotativas de sua estrutura mental, cultural e física". Para esclarecer essa colocação, a propõe coloca a seguinte questão: "Quem não reconhece a Paris moderna nas telas dos pintores impressionistas como Manet, Monet, Renoir e outros? Ou São Petesburgo retratado nos textos de Dostoievsk? Ou, ainda, a Paris de Baudelaire, Londres de Dickens? A Nova York de Woody Allen? Ou a São Paulo de Mário de Andrade e de Caio de Alcântara Machado?" (LIMENA, 2004, p. 42)

Por se constituir em um espaço cuja principal característica é a provisoriedade imagética, devido à sua constante metamorfose, a cidade moderna também se encontra sob o domínio da temporalidade, que pressupõe aspectos que envolvem a característica do provisório, do transitório, do contingente, do fugaz. Não por acaso, esse mundo se inunda de sentido quando analisado a partir da estética baudelariana, uma referência que se impõe como integrante desse novo conceito de mundo, cujo modelo interpretativo influencia todo o pensamento da crítica da modernidade. A reputação de Baudelaire desenvolveu-se ao longo dos 100 anos após sua morte. Conforme observou Bermam (1986), quanto mais seriamente a cultura ocidental passou a preocupar-se com o advento da modernidade, "tanto mais apreciamos a originalidade e a coragem de Baudelaire, como profeta e pioneiro. Se tivéssemos que apontar um pioneiro modernista, Baudelaire seria, sem dúvida, o escolhido".

É nessa Paris, de Baudelaire, caracterizada pela experiência da modernidade, que surge a atividade de flanar (a flanerie) "da qual nos fala Benjamin, em seus estudos sobre Baudelaire, como também o próprio Baudelaire já tinha mencionado em sua obra As flores do mal" (CANTINHO, 2002, p. 4). Essa atividade, a flanerie, consistia na ocupação privilegiada do burguês ocioso (flaneur). $\bigcirc$ flaneur é o personagem que ante o trânsito e o movimento da cidade grande, ante a Paris do século 19, fervilhante e mundana, busca uma poética da brevidade. Segundo o escritor Nelson Brissac Peixoto, "o tema flanerie implica uma teoria da visão. Justamente para mostrar que não se trata de mais um olhar imediato, como daquele que contempla uma paisagem". Para explicar a origem do termo, Peixoto (1996, p. 84) explica: "Baudelaire usa o termo flaneur para definir o tipo de observação que ele admira no pintor parisiense Peter Guys." Este pintor utilizava a figura do transeunte e a poética baudelariana como lente através da qual se podia ver a vida parisiense.

A flanerie é, então, essa nova forma de percepção do mundo que as grandes cidades geraram. 
"Assim que compreendemos o transitório como uma experiência moderna, que se encontra na moda, nos jornais, nos meios de transporte e na vida cotidiana, compreendemos, também, a condição humana de ser da ambigüidade. Condição que expressa um olhar para adiante e outro para trás. Sempre essa disputa contrastada entre o futuro - a novidade, a projeção para frente - e para trás, em um resgate de elementos do imaginário da tradição." (FURTADO, 2002, p. 13).

É importante observar que é nas metrópoles - essa criação da modernidade - o lugar onde habita o flaneur e todo seu prazer pelo efêmero, o transitório e o lugar da passagem. Porém, é nessa mesma metrópole - de imagem de transitoriedade - que ele busca extrair o eterno. $O$ flaneur toma como sua a tarefa de encontrar a beleza misteriosa que existe no fugaz.

Da mesma forma que as estações do ano, a moda também é pontuada pelos ciclos da natureza, identificando as mudanças de cada estação. Em contraponto ao personagem de Baudelaire, encontramos em Italo Calvino, no livro Marcovaldo ou as estações na cidade, a figura de outro personagem. Marcovaldo é um sonhador que busca a natureza em plena selva da cidade industrial. Mas onde se encontra essa natureza? Marcovaldo não tem olhos adequados para os signos da vida urbana. A cada estação, Marcovaldo busca os cogumelos que brotam no ponto de ônibus ou o mofo das bancas de jornais. Assim o autor descreve seu personagem:

"Já uma folha amarelando num ramo, uma pena que se deixasse prender numa telha, não the escapavam nunca: não havia mosca no dorso de um cavalo, buraco de cupim numa mesa, casca de figo se desfazendo na calçada que Marcovaldo não observasse e comentasse, descobrindo as mudanças da estação, seus desejos mais íntimos e as misérias de sua existência." (CALVINO, 1994, p. 7)

Marcovaldo não tem os olhos do flaneur. Não pode olhar cartazes, vitrines, letreiros luminosos. Seus olhos não estão prontos para a chegada das estações, que agora, na cidade, brotam nos lançamentos das coleções de primavera, outono, inverno e verão. A fábula de Calvino expõe o personagem Marcovaldo em estado de melancolia, enquanto o flaneur de Baudelaire só tem olhos para a novidade. A relação dialética que se estabelece pela metáfora dos personagens de Calvino e Baudelaire parece criar um sentido de mundo a expressar a tensão entre a melancolia de Marcovaldo e a embriaguez do flaneur, ao experimentar as novidades da cidade moderna. Diante dessas duas condições, encontra-se o desafio maior de pensar o sujeito moderno e a experiência da vida moderna.

As metrópoles são os lugares onde se concentram as grandes e fundamentais questões da sociedade. Lugar onde a intensidade dos estímulos põe sob ameaça o indivíduo, conforme constatou Georg Simmel. Por isso, a importância de tentar entender o modo como ocorre o processo de percepção ambiental nas cidades, compreendendo antes, de mais nada, o modo como cada indivíduo experimenta a vida cotidiana das grandes cidades. 


\section{OS SENTIDOS DA CIDADE}

As cidades fazem parte da existência humana há pelo menos sete mil anos. Considerada como um organismo vivo de nosso ecossistema, nela estão marcados os grandes avanços e recuos da humanidade. Segundo Dantas (2004, p. 1), a história nos dá conta que, ao longo desse período, a idéia de civilização, da humanidade, confunde-se com o processo de configuração do espaço urbano. É nesse contexto que, na Idade Média, costumava-se dizer que "os ares da cidade libertam...". Essa associação do espaço da cidade com a sensação da liberdade é explicada por Milton Santos, em seu livro Metamorfoses do espaço habitado (1988). Neste (p. 53), o autor escreve: "na transição no feudalismo para o capitalismo, quando as terras pertencem aos senhores feudais, a cidade aparece como o lugar do trabalho livre. O burgo, lugar onde o trabalho livre é possível..."

Com o decorrer do tempo, esse sentido da cidade como portadora da liberdade, da civilidade e da emancipação, vai se confirmando, sobretudo, com a chegada da revolução industrial, no século 19, quando a cidade se transforma no palco principal das grandes transformações da humanidade. Essas transformações ocorrem, sobretudo, nos aspectos demográficos, tecnológicos, sociais e políticos, caracterizando, definitivamente, o espaço das cidades como "o lugar revolucionário" do qual nos fala Milton Santos (1988). Atualmente, estima-se que aproximadamente $50 \%$ da população do globo vivem e morrem nas cidades. De acordo com as projeções apresentadas por Dantas (2004, p. 2), para as próximas décadas, "cerca de 80\% da população do planeta viverá e trabalhará em aglomerações de mais de 100.000 habitantes. Figurarão no cenário mundial, metrópoles com mais de dez milhões de habitantes, dentre as quais estarão cidades como São Paulo, Rio de Janeiro, Nova York, Bombaim e Moscou".

Também no campo das projeções, Marshall McLuhan sugeriu, em 1960, que o mundo inteiro iria se tornar, um dia, uma "aldeia global", onde todos os membros da humanidade poderiam interagir em um simulacro, em tempo real, de uma sociedade unitária. Passados 40 anos, a presença das assim chamadas comunidades virtuais expressa, de certo modo, a realização dessa profecia. Por outro lado, conforme lembra Limena (2004, p. 37), existem os movimentos que preconizam o "retorno à natureza" como alternativa, "por meio de comunidades rurais às margens da civilização urbanizada, enquanto outros movimentos também têm pregado os kibbutzen urbanos, localizados no coração de grandes cidades como Londres, Paris e Nova York".

Ao referir-se às formas e ao traçado das cidades, Castells (2000, p. 304) afirma que "o espaço está carregado de sentidos". De fato, ao olhar para as grandes cidades, chamam a nossa atenção o tráfego, as edificações, os movimentos das pessoas e as diferentes combinações de informações que, depois de reestruturados em nossa mente, possibilitam a elaboração de uma série de associações a partir da qual podemos constituir um denso e rigoroso espaço simbólico. É com esse paradigma, a processar-se por meio dos diversos mecanismos de percepção, que o próprio espaço se converte em uma categoria do pensamento e da experiência simbólica. Uma experiência a 
qual, assim como ocorre na metáfora do hipertexto, criada por Pierre Lévy, na qual se estabelece uma analogia entre as comunidades reais e as comunidades virtuais, estabelece-se um elo entre o real e o mental, entre o verdadeiro e o simbólico, entre o concreto e o imaginário.

As análises a respeito das cidades contemporâneas tendem a apresentá-las com um cenário caótico, sombrio e ameaçador. A estrutura aberta pelo progresso cria, no imaginário do homem, uma paisagem que deriva de seus produtos mais expressivos como os arranha-céus, reatores atômicos, terrenos suburbanos ocupados indiscriminadamente, centros comerciais, aeroportos internacionais, parques, shopping centers e tudo o mais que compõe a paisagem contemporânea. Diante de tal perspectiva, "como devemos pensar e projetar o futuro, de forma a garantir uma realidade urbana que possa ser vivida como experiência humana, individual e coletiva?" (LIMENA, 2004, p. 43). A resposta a essa questão, segundo a autora, é a prática baseada em princípios morais e culturais. "Torna se urgente um enfrentamento dos desafios postos que, também, possibilite reencantar a consciência sociopolítica-cultural: há que se reconhecer as utopias, de modo a fazer frente ao ceticismo doentio e ao ceticismo desabusado; ... Ética, estética e política devem e podem andar juntas para pensar o habitar ou o viver na cidade."

A organização do espaço urbano nos diversos contextos históricos depende, fundamentalmente, dos fatores de influência que caracterizam cada um desses momentos. Com a dinâmica das transformações em curso, o que se verifica, no momento atual, é a tendência, apontada por muitos autores, à consolidação de uma sociedade globalizada, caracterizada pelo aumento significativo de produção em ciência, tecnologia e informação. Essa nova dinâmica de produção, denominada por Milton Santos (1994), de meio "técnico-científico informacional", vem ocorrendo de forma extensa e contínua nos lugares mais desenvolvidos, como os Estados Unidos, o Japão, a Europa e parte da América Latina. Em outros lugares como a África, parte da Ásia e parte da América Latina manifestam-se apenas como manchas e pontos. Os caixas eletrônicos, os telefones celulares e os computadores conectados à internet representam apenas parte da pequena parcela visível desses espaços "carregados" de ciência, técnica e informação.

A emergência desse novo modelo de sociedade é atribuída ao surgimento de um paradigma tecnológico cujas características organizacionais estariam redesenhando a geografia econômica mundial. Trata-se de um processo cujas origens se encontram nas transformações ocorridas nos meios de produção, com a introdução de novos modelos produtivos e, por conseqüência, o aprofundamento da divisão entre trabalho manual e intelectual, com a crescente concentração nos processos de geração de conhecimento. Em uma análise aprofundada a respeito desse processo, a arquiteta Rose Compans (1999), em seu artigo "O Paradigma da Global Cities", observa que, nesse novo modelo organizacional, o destaque maior é dado para o reconhecimento da qualidade do conhecimento e do processamento da informação. Esses, por sua vez, convergem para a valorização da matéria-prima e da produtividade, deixando, para o segundo plano, as preocupações com os meios e as formas de produção existentes no período predominantemente industrial, conforme a constatação a seguir: 
"Uma primeira abordagem do novo papel das cidades é aquela que associa a sua gênese à emergência de um novo modelo de organização sociotécnica da produção, das novas tecnologias da informação, simultaneamente à reestruturação do capitalismo, em particular, no que concerne ao processo de internacionalização do capital que, juntos estariam conformando um novo 'espaço de fluxos' em substituição ao 'espaço dos lugares'. O elemento central da produtividade no novo modo de desenvolvimento informacional, que sucede ao industrial, baseia-se agora na qualidade do conhecimento e no processamento da informação, convertida ao mesmo tempo em matéria-prima e produto, e não mais nas fontes de energia e na qualidade de seu uso, como no modelo anterior." (COMPANS, 1999, p. 92)

Paralelamente, o constante desenvolvimento tecnológico, principalmente no campo das telecomunicações, associado ao da informática (telemática), vem provocando um processo crescente de aceleração de fluxos em nível global, fenômeno este que faz com que predomine a impressão de dissolução de fronteiras entre as nações, economias e culturas. Essa mobilidade, de acordo com a autora, acentua "a expansão da indústria financeira, decorrente da extraordinária mobilidade do capital induzida pela dispersão geográfica do setor industrial, não apenas por deslocamentos massivos de plantas industriais, mas, sobretudo, graças à transnacionalização da propriedade por intermédio do investimento estrangeiro direto". (COMPANS, 1999, p. 94)

Ainda em uma abordagem sobre o novo aspecto das grandes cidades, Compans (1999, p. 97) faz referência à reflexão de David Harvey (2000, p. 140), segundo o qual a pós-modernidade surge como expressão cultural desse novo regime de acumulação, caracterizado, agora, pela flexibilidade em contraposição ao regime fordista. Assim, também no aspecto sociocultural, a sociedade passa a transformar sua dinâmica e, por conseqüência, a transformar seu meio. Em sua análise da obra de Harvey, a autora constata:

"Sua 'démarche' parte do pressuposto de que um regime de acumulação não se apóia apenas em determinada organização sociotécnica da produção, mas se traduz nos modos de vida social, aí compreendidas suas formas de consumo. A aceleração dos ritmos da produção e da inovação, implica a aceleração dos ritmos do consumo, algo que requer como contrapartida uma mudança no padrão do consumo. A difusão da cultura do efêmero e do descartável, que envolve a manipulação do gosto e da opinião, e a construção de novos sistemas de valores comportamentais e estilos de vida são condições necessárias, ainda que não suficientes, do regime de acumulação flexível, para as quais se destaca a importância da industria cultural e das mídias, essencialmente urbanas." (COMPANS, 1999, p. 97)

As cidades pós-modernas seriam, então, na visão da autora, "o lugar privilegiado onde gostos, modos de vida e estilos são permanentemente criados e recriados, onde a volatilidade da moda pode ser mobilizada e apropriada, e onde a cultura pode ser mercantilizada, assim como somente nelas se situam os trabalhadores 'imateriais' que são os produtores ou manipuladores desses novos sistemas de signos e imagens". É nesse ambiente, de fluxos e ritmos acelerados, de transformação constante, no qual predomina a efemeridade e também o "virtual", que emergem as sociedades pós-industriais, cuja 
característica principal reside no crescimento do setor de serviços especializados. Ainda segundo Compans (1999, p. 104), o crescimento desse setor de serviços, ocorreria "de forma dissociada da produção industrial, que segue sendo a base material das riquezas das nações, dando origem a hipótese da especialização das cidades na economia de serviços".

As mudanças impostas pela nova divisão social do trabalho, que deixa de ser predominantemente industrial, passando a ser caracterizado pelo "terciário avançado", refletem, decisivamente, nos modelos de urbanismo das cidades pós-industriais. Os principais fatores que passam a determinar as mudanças espaciais são, segundo Compans (1999, p. 108), a dispersão geográfica da produção e a concentração das funções de comando, que passam a ditar os novos imperativos do urbanismo, que consistem na implantação de infra-estruturas inovadoras, adequadas ao novo modelo de gestão urbana. As estruturas exigidas vão desde redes de comunicação em fibra ótica para a viabilização de "edifícios inteligentes", estações terrestres de telecomunicações (teleportos) que propiciem operacionalidade às economias de aglomeração, infra-estrutura de transportes de alta velocidade (aeroportos e TGV's) para assegurar acessibilidade física e estruturas residenciais que ofereçam qualidade de vida com equipamentos comerciais, culturais, esportivos e de lazer.

"... tão logo uma região do mundo se associa à economia global, dinamizando sua economia e sociedades locais, o requisito indispensável é a constituição de um núcleo urbano de gestão de serviços avançados organizados, invariavelmente, em torno de um aeroporto internacional: um sistema de telecomunicações por satélite: hotéis de luxo, com segurança adequada; serviços de secretariado em inglês; empresas financeiras e ou consultoria com conhecimento da região; oficinas de governos regionais e locais capazes de proporcionar informação e infra-estrutura de apoio às inversões internacionais: um mercado de trabalho local com pessoal qualificado em serviços avançados e infra-estrutura tecnológica." (BORJA; CASTELLS apud COMPANS, 1999, p. 109)

Dessa forma, a globalização poderia ser definida, de acordo com Compans (1999), como um processo no qual a articulação entre o global e local ocorre sem a interferência das esferas regional e nacional. Para a autora, as cidades globalizadas passam a constituir-se em "centros nodais" dotados de infra-estrutura urbana suficiente para satisfazer as necessidades técnico-sociais que podem ser traduzidas em "uma rede de serviços avançados, tecnologia de comunicação e informação, além de uma especialização financeira". Por último, esses "centros nodais" se caracterizam, também, por proporcionar uma qualidade de vida atraente ao pessoal altamente qualificado proveniente de empresas multinacionais.

Naturalmente existem regiões que, há muito, beneficiam-se dessa geografia global. Borja e Castells (apud COMPANS, 1999, p. 101) consideram que é na articulação entre o global e o local que se encontra, em última instância, "a fonte dos novos processos de transformação urbana e, portanto, os pontos de incidência de políticas urbanas, locais e globais, capazes de inverter o processo de deterioração da qualidade de vida nas cidades". Ainda segundo esses autores, "tal otimismo re- 
side na constatação, empírica, de que os novos processos produtivos considerados 'estrategicamente dominantes', tidos como os serviços avançados e a indústria de alta tecnologia, são aqueles que apresentam o maior dinamismo econômico, com mais rápido crescimento no emprego e na proporção do PIB da maioria dos países, e são também essencialmente urbanos". Essa estrutura de serviços urbanos segue um modelo hierárquico de concentração metropolitana, constituindo uma rede policêntrica com três níveis de hierarquia urbana, conforme o modelo apresentado por Rose Compans (1999, p. 101) que descrevemos a seguir:

a) As funções mais importantes em termos de qualificação, poder e capital, como as finanças internacionais, consultorias e serviços às empresas no âmbito internacional, concentram-se nas principais áreas metropolitanas do mundo, ou seja, em Nova York, Londres e Tóquio;

b) as funções de segundo nível, mas também ligadas à gestão global, e alguns segmentos de mercados específicos - como o de opções de futuro -, encontram-se concentradas em grandes cidades mundiais, como Chicago, Los Angeles, São Francisco, Hong Kong, Singapura, Osaka, Frankfurt, Paris, Zurique, Amsterdã e Milão;

c) as funções destinadas à incorporação de novos mercados, na medida em que a rede de interações em que se baseia a economia global se estende, faz emergir "centros regionais", como as cidades de Madri, Barcelona, São Paulo, Buenos Aires, México, Taipei e Moscou.

Apesar de a globalização influenciar, de maneira decisiva, todos os lugares do planeta, existem lugares privilegiados, onde o processo se manifesta com maior intensidade devido à configuração de um meio técnico-científico informacional, presente com maior vigor. Segundo Firmino (2000, p. 69-70), em sua dissertação de mestrado, são "lugares onde as modificações globais da sociedade se dão mais rapidamente, (...) regiões complexas, formadas por cidades e locais de influência onde a tecnologia flui com mais facilidade, tanto quanto a sua produção, quanto pelo seu uso". Ainda segundo o autor, essas regiões se caracterizam por sua "atratividade" tecnológica devido às grandes concentrações de demanda e, principalmente, de produção tecnológica, constituindo-se em verdadeiras "vitrines" do meio técnico-científico informacional.

Chamadas de "regiões dinâmicas em inovação" (FIRMINO, 2000, p. 70), esses lugares se caracterizam pela presença marcante dos "espaços inteligentes". Esses espaços são formados pelos setores produtivos da economia e por centros de pesquisa e desenvolvimento (universidades e institutos de pesquisa) que se relacionam dentro desse ambiente propício, gerando mão-de-obra qualificada, evolução da própria tecnologia desenvolvida e uma demanda por novos avanços relacionados ao setor. Os "espaços inteligentes" podem ser identificados em dois segmentos, de acordo com as suas relações tecnológicas: espaços relacionados ao uso de tecnologia, ou espaços relacionados à produção de tecnologia. Ainda, de acordo com o autor, "os lugares 
onde predominam os espaços inteligentes, ligados à produção tecnológica, são mais raros. (...) São, portanto, lugares especializados qualificados ao desenvolvimento tecnológico com grandes concentrações de produção científica". Dessa forma, Firmino (2000, p. 71) introduz outro conceito diretamente ligado ao espaço inteligente da produção de tecnologia, denominado de "cidades da inteligência". A relação entre essas três instâncias do meio técnico-científico informacional é explicada da seguinte forma pelo autor:

"Uma região dinâmica, em inovação, necessita de avanços tecnológicos específicos inerentes às especializações da sua produção, tendo que buscá-los nas chamadas cidades da inteligência, marcadas pela presença de espaços inteligentes ligados à produção de tecnologia, cidades onde se acumulam atividades relacionadas diretamente ao desenvolvimento tecnológico, apresentando altos graus de produção de conhecimento e de produção de bens com altos valores tecnológicos agregados.

Normalmente, na bibliografia, sobre os casos brasileiros, estas cidades da inteligência são referenciadas segundo o conceito de pólos de desenvolvimento tecnológico." (FIRMINO, 2000, p. 71)

Cabe ressaltar que a temática, aqui abordada, insere-se em um contexto isolado da realidade da maior parte das cidades brasileiras. Portanto, é importante destacar que, conforme ressalta o autor, as chamadas "regiões dinâmicas em inovação e mesmo as cidades da inteligência, são fenômenos novos, em pleno desenvolvimento, que se sobrepõem a realidades distintas e datadas de outros tempos" (FIRMINO, 2000, p. 72). Com essa afirmação, o autor atenta para outra questão relevante da realidade urbana brasileira - os evidentes contrastes presentes na cidade contemporânea. É possível que as "cidades da inteligência" sejam os lugares de maior sintonia com o movimento do mundo e de maior evidência das relações tecnológicas, mas podem também apresentar os maiores contrastes do ponto de vista social e cultural no modo de produção da sociedade contemporânea.

\section{Bibliografia}

BERMAN, Marshal. A aventura da modernidade. Tudo que é sólido desmancha no ar. São Paulo: Companhia das Letras, 1986.

CALVINO, Italo. As cidades invisíveis. São Paulo: Companhia das Letras, 1990.

Marcovaldo, ou as estações na cidade. São Paulo: Companhia das Letras, 1994.

CANTINHO, Maria João. Modernidade e Alegoria em Walter Benjamin. Agulha - Revista de Cultura. Fortaleza São Paulo, 2002. Disponível em: http://www.revista.agulha.nom.br/ag29benjamin.html. Acesso em: 11 maio 2004.

CASTELLS, Manuel. A questão urbana. Tradução de Arlene Caetano. Rio de Janeiro: Paz e Terra, 2000.

COMPANS, Rose. O paradigma das global cities nas estratégias de desenvolvimento local. Revista Brasileira de Estudos Urbanos e Regionais. São Paulo: Edusp, n. 1, 1999.

DANTAS, Eugênia Maria. Polifonia: a linguagem da cidade. Mneme-Revista de Humanidades. v. 3, n. 9, jan./mar. de 2003. Disponível em: http://www.seol.com.br/mneme/ed1/. Acesso em: 16 set. 2004.

FERRARA, Lucrécia D’Alésio. Cidades ilegíveis. percepção ambiental e cidadania. In: FIRMINO, Rodrigo José. Espaços inteligentes. O meio técnico-científico informacional e a cidade de São Carlos (SP). 2000. Dissertação (Mestrado em Arquitetura e Urbanismo), EESC, Universidade de São Paulo, São Carlos, 2000. 
FURTADO, Beatriz. Meios de comunicação e experiência espaço-temporal. INTERCOM, 2002. Sociedade Brasileira de Estudos Interdisciplinares da Comunicação. IN: CONGRESSO BRASILEIRO DE CIÊNCIAS DA COMUNICAÇÃO, 25. Salvador: Disponível em: http://www.intercom.org.br. Acesso em: 16 set. 2004.

GNOATO, Luís Salvador. Blade Runner. A cidade pós-futurista. Disponível em: http://www.vitruvius.com.br/arquitextos/arq053/arq053_01.asp. Acesso em: 21 jul. 2005.

LIMENA, Maria Margarida Cavalcanti. Cidades complexas no século XXI. Ciência, Técnica e Arte. PUC-SP. Disponível em: http://www.scielo.br/pdf/spp/v15n3/ a06v15n3.pdf. Acesso em: 25 set. 2004.

PEIXOTO, Nelson Brissac. Paisagens urbanas. São Paulo: Senac, 1996.

PELLEGRINO, Carlos Tranquilli. Patrimônio cultural urbano: De quem? Para o quê? Ciudad Antrpologica - Ciudad Virtual de Antropologia e Arqueologia. Argentina. 2002. Disponível em: http://www.naya.org.ar/congresso2002/ ponencias/ carlos_tranquilli_pellegrino.htm. Acesso em: 05 out. 2004.

SANTOS, Milton. Técnica espaço tempo. Globalização e meio técnico-científico informacional. São Paulo: Hucitec, 1994.

. Técnica e tempo. Razão e emoção. A natureza do espaço. São Paulo: Hucitec, 1997.

. Pensando o espaço do homem. São Paulo: Hucitec, 1997.

. Metamorfoses do espaço habitado. São Paulo: Hucitec, 1997.

SOUZA, André Pereira de. Cidades reais e imaginárias no cinema. Disponível em: http://www.vitruvius.com.br/arquitextos/arq000/esp287.asp. Acesso em: 21 jul. 2005. 